\title{
Risk Impact Analysis across the Phases of Software Development
}

\author{
Raghavi K. Bhujang and Suma V.
}

\begin{abstract}
Successful development of software project in any organization is achieved by ensuring that the delivered system meets the expectations of the customer. Aforementioned objective can be achieved by overcoming the constraints that hinder the path of success. These hindrances emerge as risks that might cause the possibility of failure while procuring the customer satisfaction in software organization. Risk therefore should be resolved by implementing preventive measures which avoids the occurrence of risk or even by planning the mitigation when its occurrence is unavoidable. It is further proven that Cost, Time, People and Process $\left(\mathrm{CTP}^{2}\right)$ which are some of the success factors of any project will surface as risks if overlooked.

This paper therefore focuses on analyzing the impact of these risks across all the phases of software development which are categorized in terms of short term and long term projects. This mode of analysis enables the developer to comprehend and thereby manage the risks more effectively.
\end{abstract}

Index Terms - Risk management, risk analysis, risk factors, software engineering, software development process, software development life cycle.

\section{INTRODUCTION}

A successful software development process includes the details of each and every step of the process which are called as phases of development process. In general, these phases can be defined as requirement phase being the initial one, where the customer expectations are converted to business goals that are in turn defined in terms of project goals. Design phase being the next, the designer/developer decides on the topology of the architecture of the project. In the subsequent phase, this topology is coded by making use of the software specifications. Consequently, in the Testing phase, developer will be able to verify or validate the code along with the data against the business requirements. In this whole process, there will be several challenges that the developer has to overcome to reach the final completion stage followed with the delivery of the project.

According to authors of [1], risks can be measured in terms of $\mathrm{CTP}^{2}$ - Cost, Time, People and Process to understand the impact in the project. And these terms/parameters need to be tracked and measured for each of the project phase defined above starting from requirements up to testing.

To evaluate $\mathrm{CTP}^{2}$, each developer in the software projects should be inculcated with the knowledge of business

Manuscript received January 15, 2014; revised March 20, 2014.

Raghavi K. Bhujang is with Dept. of MCA, PESIT, Bangalore, and Industry Incubation Centre, Jain University, RIIC, DSI, Bangalore, India (e-mail: raghavi@pes.edu).

Suma V. is with Research and Industry Incubation Centre, Dayananda Sagar Institutions, Bangalore, India. requirements to understand the process in terms of each of the development phase.

This paper is organized in the following manner: Section II of the paper emphasizes on the same work area being done from different research scholars. Section III focuses on analyzing the risk probability index in long term and short term projects. Section IV provides information about the different projects and the risks faced by the same in terms of these projects. Section $\mathrm{V}$ focuses on the inferences that can be drawn by these two types of projects and Section VI gives the representation of common risks in terms of Venn diagram for these projects. And finally Section VII talks about summary of the overall investigation.

\section{LITERATURE SURVEY}

Authors of [2], have focused on Small and Medium Software Development Projects and the risks involved in the same. They made an analysis of occurring risks by taking the assessment parameters as focus, proposes, description, inputs, risk ranking, decision taking types, and Prototype involved in these projects.

Authors of [3] have analyzed the risks related to web and distributed software development projects. They have also suggested to develop an improved approach to measure and control web and distributed development risks.

Authors of [4] have investigated the state of risk and risk management in the most popular software development process models (i. e. waterfall, v-model, incremental development, spiral, and agile development).

Authors of [5] have demonstrated the need for an intelligent risk assessment and management tool. They have proposed a model, whose development is subject of further research, which can be investigated for use in developing intelligent risk management tools.

Authors of [6] have proposed a new conceptual framework for managing risk in software development projects, introduced new conceptual factors, bringing out their interrelation, and suggested new prospects and managerial implications for both practitioners and academics.

Further, Authors of [7] have done risk classification into one of the three risk groups namely cost, time and quality which is an outcome of investigation on risk sources in design and build projects using the discriminant analysis technique.

Authors of [8] have suggested an approach for the assessment of risks in globally distributed software projects with a stochastic simulation technique to identify factors that impact team productivity. Authors of [9] have measured these software development risks in terms of Cost, Time, People and Process $\left(\mathrm{CTP}^{2}\right)$ to understand the impact of the 
same in the project. They have also classified various Risks based on the impact analysis which is conducted in terms of $\mathrm{CTP}^{2}$.

Authors of [10] have introduced a Risk Management Tool that identifies the risks, in terms of cost and time that can be resolved by rescheduling of the work through resource management.

Authors of [11] have proposed an automated tool for risk management that further leads towards immediate call for risk resolving strategies towards development of sustainable and high quality products.

Authors of [12] have inferred that occurrence of risk is always high irrespective of long term or short term project. Also, the impact of risk on long term projects is higher when compared to the impact of risk on short term projects which is validated against $\mathrm{CTP}^{2}$ (Cost, Time, People, and Process).

\section{ANALYSIS OF RPI}

Risk in software industries is considered to be a chance of occurrence of failure or probable failure. Despite the quality standards like SEI-CMMi or PCMMi or Six Sigma being shadowed as some of the global standards, there will be many loop holes in the software development that needs to be identified and resolved. Witlessness of these risks can be a great loss for the organization depending on the nature and the impact of precious area / resources.

According to authors of [12], the nature of the risk can be of 4 different types depending on the Risk Index Level (RIL). The Table I shows that nature can be categorized as Low (RIL - up to $25 \%$ ), Moderate (RIL - up to 50\%), High (RIL - up to $75 \%$ ), Very High (RIL - above $75 \%$ ).

TABLE I: NATURE OF RISK WITH RIL

\begin{tabular}{cc}
\hline \hline Nature of Risk & Description of Nature \\
\hline Very High Risk (RIL $>75 \%)$ & Work Stopper \\
High Risk $(>50 \%$ RIL $<75 \%)$ & Deployment / Syntax error \\
Moderate Risk $(>25 \%$ RIL $<50 \%)$ & Work Stopper at some conditions \\
Low Risk (RIL $<25 \%)$ & Cosmetic \\
\hline \hline
\end{tabular}

As shown in Table I, these different types in nature of risk are defined with description in terms of impact. They can be demarcated as Cosmetic, Work Stopper at some conditions, Deployment / Syntax error and complete Work Stopper respectively.

Risk Probability Index (RPI) defines the possibility of occurrence, type of occurrence and number of occurrences of these risks in projects.

\begin{tabular}{lll} 
& TABLE II: RPI FOR SHORT TERM PROJECTS \\
\hline \hline $\begin{array}{l}\text { Possibility of } \\
\text { occurrence }\end{array}$ & $\begin{array}{l}\text { Probable type of } \\
\text { occurrence }\end{array}$ & $\begin{array}{l}\text { Number of } \\
\text { occurrences }\end{array}$ \\
\hline 1 & Very Frequent & $>=10$ \\
& Frequent & Starting from 5 up to \\
& Rare & 10 \\
& & Starting from 1 up to \\
& Unlikely & 5 \\
\hline \hline
\end{tabular}

By collecting and analyzing several projects data from numerous industries, it was well shown that software development projects can be of two types According to industry habitual convention, projects which consumes less than six months of the complete development time are categorized as short term projects and those which take more than six months are categorized as long term projects. Table II indicates the RPI depicted for Short Term Projects by taking analysis of several projects across companies and taking count of risks that occur in duration of 5 days.

By studying several such projects, it is consequent that the risks that appear in the development process are of different types depending on the probability of occurrence.

Prior to the analysis of probability of occurrence, a risk can be either true (0) or false (1) which means a risk can either occur or cannot occur at all. As cited in Table II, conferring to the investigated projects across the companies under this investigation, all the risks that occur in five days duration are counted. Accordingly, those risks that occur 1 to 5 times in a project are convened to be of the rare type. And the risks which are more than 5 in number up to 10 are deemed to be of frequent type and 10 or more number of times occurring risks are said to be of very frequent type.

And when the possibility of occurrence value is 0 for a risk, then its probability type of occurrence is said to be of unlikely type since it will not occur at all, and hence the value for number of occurrences will also be 0 .

Further moving this investigation towards the long term projects, Table III is drawn by reckoning the occurring risks that happen in duration of one month.

\begin{tabular}{lll}
\multicolumn{2}{c}{ TABLE III: RPI FOR LONG TERM PROJECTS } \\
\hline \hline $\begin{array}{l}\text { Possibility of } \\
\text { occurrence }\end{array}$ & $\begin{array}{l}\text { Probable type of } \\
\text { occurrence }\end{array}$ & $\begin{array}{l}\text { Number of } \\
\text { occurrences }\end{array}$ \\
\hline 1 & Very Frequent & $>=20$ \\
& Frequent & Starting from 8 up \\
& to 20 \\
& Rare & Starting from 1 up \\
& to 7 \\
0 & Unlikely & 0 \\
\hline \hline
\end{tabular}

According to Table III, all those risks that occur 1 to 7 times in a project (within the duration of one month) are convened to be of the rare type. The risks which are more than 7 in number up to 20 are deemed to be of frequent type and 20 or more number of times occurring risks are said to be drastic in number and their probable type of occurrence is of very frequent type.

Similar to short term projects, when the possibility of occurrence value is 0 for a risk, then its probability type of occurrence is said to be of unlikely type since it hardly occurs and hence the value for number of occurrences will also be 0 .

\section{RISK IMPACT ANALYSIS}

It is easy to mitigate or avoid most of the occurring risk in software development by visualizing the root cause analysis. This can be accomplished by keeping track of entire process of development. The Table IV provides the details of risks that occur in each of the phases of software development, their impact type, and the number of time each of the risk occurs and Risk Probability Index (RPI). The data is random sampled from different short term projects from various software development industries. Despite the detailed root cause analysis, there exists many risks that are unidentified in 
the development process, where categorizing them as a part of any of the phases of development would be challenging. Schedule management risks and resource management risks are few of such instances. Further, it would be easier to identify and manage those risks when they are a part of the development phase by navigating through the known phases. Fig 1 depicts the short term projects where risks appear in the various phases along with the RPI.

\begin{tabular}{|c|c|c|c|c|c|}
\hline Phase & Risks & Risk Description & Impact / Nature of Risk & $\begin{array}{l}\text { Number of } \\
\text { occurrences }\end{array}$ & $\begin{array}{l}\text { Risk Probability } \\
\text { Index }\end{array}$ \\
\hline \multirow{5}{*}{$\begin{array}{l}\text { Requirements Gathering } \\
\text { - Phase } 1\end{array}$} & Risk 1 & $\begin{array}{l}\text { Different Language for } \\
\text { Communication }\end{array}$ & High & 10 & Very Frequent \\
\hline & Risk 3 & $\begin{array}{l}\text { Delaying the } \\
\text { documentation }\end{array}$ & Moderate & 5 & Frequent \\
\hline & Risk 5 & $\begin{array}{l}\text { Inadequate Review, } \\
\text { Feedback, Closure }\end{array}$ & High & 2 & Rare \\
\hline & Risk 9 & Change in Requirements & High & 7 & $\begin{array}{l}\text { Rare, Frequent, } \\
\text { Very Frequent }\end{array}$ \\
\hline & Risk 38 & $\begin{array}{l}\text { Not redefining the } \\
\text { business rules }\end{array}$ & Very High & 3 & Rare \\
\hline \multirow{6}{*}{ Design - $\quad$ Phase 2} & Risk 8 & $\begin{array}{l}\text { Software Prototype } \\
\text { Tools not platform } \\
\text { independent }\end{array}$ & High & 6 & Frequent \\
\hline & Risk 11 & $\begin{array}{l}\text { Configuration variation } \\
\text { in component } \\
\text { development }\end{array}$ & Very High & 3 & Rare \\
\hline & Risk 17 & Gold plating & Moderate & 3 & Rare \\
\hline & Risk 20 & False Feature Rich & High & 4 & Rare \\
\hline & Risk 21 & $\begin{array}{l}\text { Programming For The } \\
\text { Future }\end{array}$ & Very High & 4 & Rare \\
\hline & Risk 43 & Improper Design & High & 3 & Rare \\
\hline \multirow{4}{*}{ Code / Build - Phase 3} & Risk 10 & $\begin{array}{l}\text { Usage of Unproven } \\
\text { Software Products }\end{array}$ & High & 6 & Frequent \\
\hline & Risk 28 & Unlicensed Software & High & 2 & Rare \\
\hline & Risk 32 & $\begin{array}{l}\text { Individual Development } \\
\text { of Components }\end{array}$ & Very High & 3 & Rare \\
\hline & Risk 37 & $\begin{array}{l}\text { Being Held Hostage by } \\
\text { Third-Party Vendors }\end{array}$ & High & 7 & Frequent \\
\hline \multirow{4}{*}{$\begin{array}{c}\text { Testing/Implementation } \\
\text { - Phase } 4\end{array}$} & Risk 32 & $\begin{array}{l}\text { Individual Development } \\
\text { of Components }\end{array}$ & Very High & 3 & Rare \\
\hline & Risk 35 & $\begin{array}{l}\text { Too little / Too much } \\
\text { formality }\end{array}$ & Moderate & 5 & Frequent \\
\hline & Risk 44 & Connectivity Issues & High & 8 & Frequent \\
\hline & Risk 45 & $\begin{array}{l}\text { Integration is required } \\
\text { between many different } \\
\text { technologies }\end{array}$ & High & 8 & Frequent \\
\hline
\end{tabular}

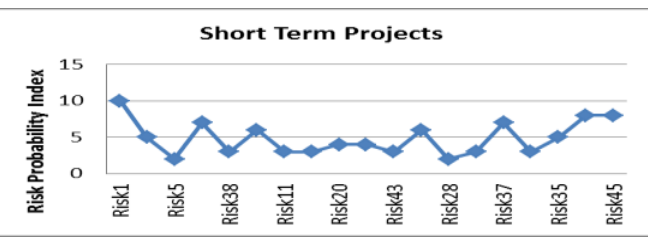

Fig. 1. Graph of occurrence of risks along with risk probability index (RPI) in short term projects.

Fig. 1 further indicates the propogation of risks from phase to phase in software development.

The inferences that can be drawn from the Table IV (Case 1), table of short term projects and the Fig. 1, Graph of the same are as given below.

\section{INFERENCES}

\section{A. Inferences on (Fig. 1-Case 1)}

- Though risk is spread across phases, the probability of those types of risks which occurs very frequently is seen at requirements phase than at any other phases.

- Probabilities of types of risks which are rare and frequent are seen in subsequent phases namely Design, Build and Test.

\section{B. Phase Wise Inference}

- Probability of Very Frequent, Frequent and Rare type of risk occurrence is same during requirements phase.

- Probability of Rare occurrences of risks is seen more in design in addition to probability of frequent occurrence of risk.

- Frequent and Rare occurrence of risk is seen in same probability in Build phase.

- However, the Test phase, the probability of frequently occurring risks are more while rare occurring risks can also be witnessed.

\section{Impact / Nature Wise Inference}


- All catastrophic (Very High) risks occur across the phases whose probability of occurrence is rare.

- However, it is design phase that is more prone to catastrophic compared to other phases.

- High risks are seen in all phases across.

- Moderate nature of risk is hardly seen in coding compared to other phases.

The Table $\mathrm{V}$ gives the details of all those occurring risks in long term projects of software development, with their impact type, number of time each of the risk occurs, and their respective Risk Probability Index.

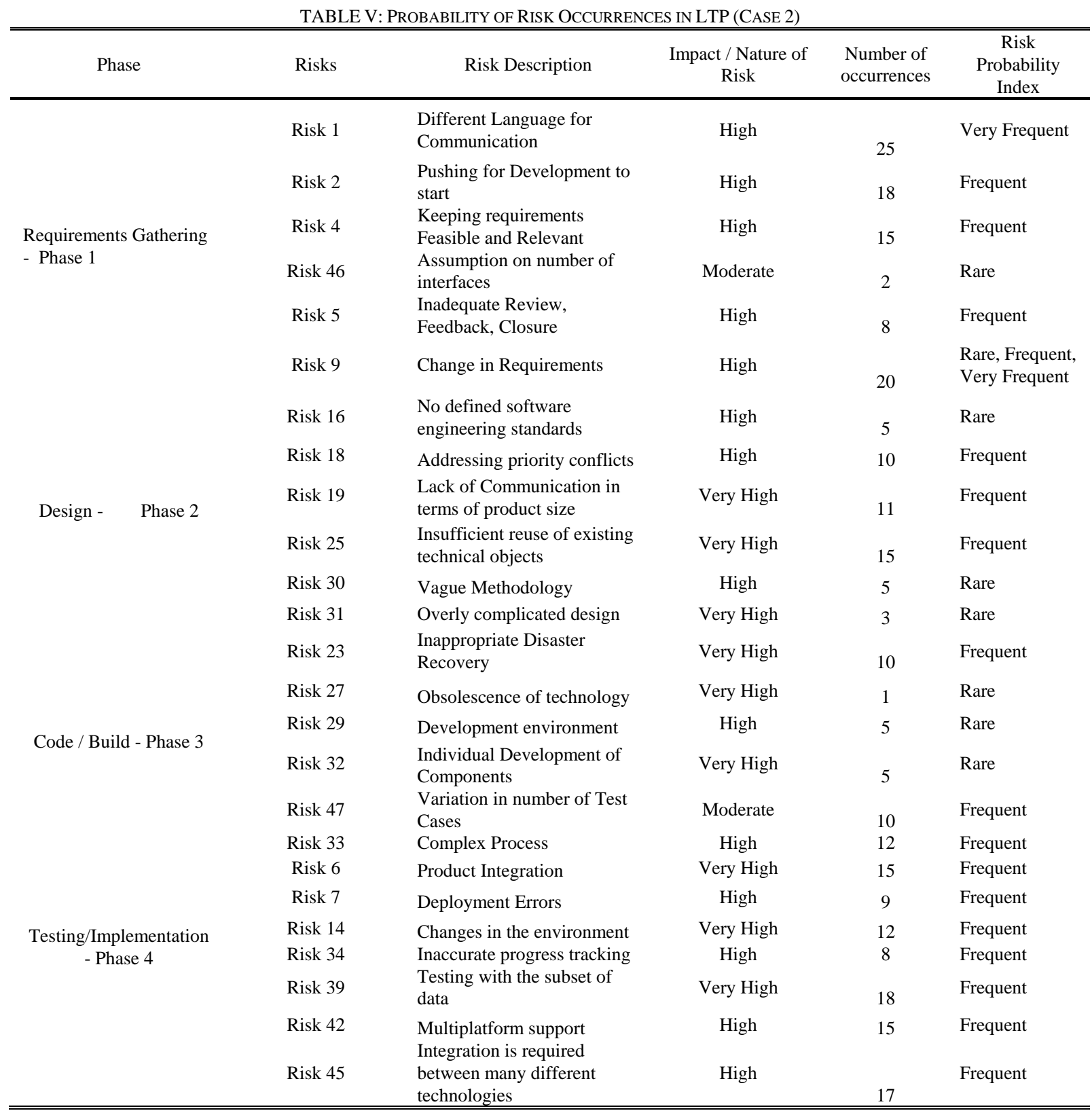

As mentioned earlier, it is easier to identify and foresee the risks that are likely to occur by navigating through the phases of software development with the help of a graph.

Fig. 2 depicts the long term projects where risks appear in the various phases along with the RPI.

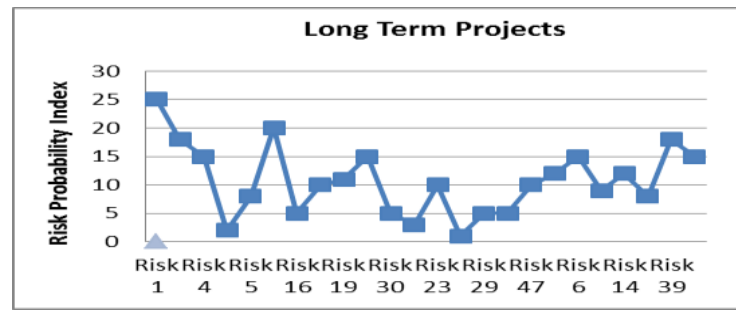

Fig. 2. Graph of occurrence of risks along with risk probability index (RPI) in long term projects.
The inferences that can be drawn from both the Table V (Case 2) and Fig. 2, graph of long term project risks are as follows:

\section{Inferences on (Fig. 2-Case 2)}

- Probability of Frequent type of risk is more compared to Very Frequent and Rare types of risks in requirements phase.

- Probability of Catastrophic (Very High) and High types of risks is more or less equally distributed across the subsequent phases whereas Moderate risk is hardly seen.

\section{E. Phase Wise Inference}

- Probability of Frequent type of risk is more during requirements phase compared to Very Frequent and Rare 
type.

- In the design phase and also the build/code phase, the probability of occurrence of frequent type of risks and rare type of risk is almost the same.

- Where as in testing phase, all/most of the risks that occur are of frequent type.

\section{F. Impact / Nature Wise Inference}

- Catastrophic (Very High) risks are less/negligible in number in requirements phase compared to the other phases.

- High risks occur more in number in requirements phase compared to the other phases.

Moderate risk is hardly seen in design phase compared to other phases.

\section{GRAPHICAL VIEW OF RISKS}

There are few risks which are observed to be common in both Short term projects(STP) and Long term projects (LTP) such as communication risk, inadequate risk etc. which is highly likely to occur irrespective of the type, duration of the project. By observing STP and LTP, it is further possible to visualize risks that can appear both in STP and LTP through the aid of set concept.

STP $($ Case 1$)=\{$ Risk1, Risk 3, Risk 5, Risk 9, Risk 8, Risk 10, Risk 11, Risk 17, Risk 20, Risk 21, Risk 28, Risk 32, Risk 35, Risk 37, Risk 38, Risk 42, Risk 43, Risk 45 \}

LTP $($ Case 2) $=\{$ Risk 1, Risk 2, Risk 4, Risk 5, Risk 6, Risk 7, Risk 9, Risk 14, Risk 16, Risk 18, Risk 19, Risk 23, Risk 25, Risk 27, Risk 29, Risk30, Risk 31, Risk 32, Risk 33, Risk 34, Risk 39, Risk 42, Risk 45 \}

STP $\cap$ LTP $=\{$ Risk 1, Risk 5, Risk 9, Risk 32, Risk 45 $\}$

It is easier to represent the relation of intersection through Venn diagram as cited in Fig. 3.

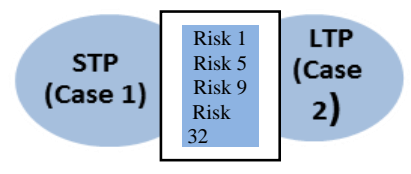

Fig. 3. Representation of intersection through Venn diagram.

Fig. 3 clearly indicates the common risks that occur both in short term projects and long term projects. The deep investigation of risks from the projects under study indicates that the risks seen appearing commonly are Risk 1 - Different Language for Communication, Risk 5 - Inadequate Review, Feedback, Closure, Risk 9 - Change in Requirements, Risk 32 - Individual Development of Components, Risk 45 Integration is required between many different technologies. There are many more that can occur in software development projects.

\section{CONCLUSION}

Every project has its own attentive challenges which need to be alleviated to make it a successful completion. From the deep observations of the short term and long term projects which are sampled from various software industries, it is apparent that, risks in software development can be identified in a more improved way by navigating through the phases.
This paper focusses on analyzing the challenges that occur across the phases of software development by taking some of the real time projects of short term and long term types. There are many risks incurred in each of the phases of software development which are analyzed along with their probability index to understand the frequency of occurrence in all these phases. Forth coming paper emphasizes on analysis of Risk Impact in terms of $\mathrm{CTP}^{2}$ (Cost, Time, People, Process) parameters across the phases of Software Development.

\section{REFERENCES}

[1] R. K Bhujang and V. Suma, " Risk measurement with $\mathrm{CTP}^{2}$ parameters in software development process," in Proc. the 48th Annual Convention of Computer Society of India - Vol II, vol. 249, Springer International Publishing Switzerland, 2014, pp. 491-498.

[2] A. M. Sharif and S. Basri, "A study on risk assessment for small and medium software development projects," International Journal on New Computer Architectures and Their Applications (IJNCAA), vol. 1, no. 2, pp. 325-335, 2011 .

[3] A. A. Keshlaf and S. Riddle, "Risk management for web and distributed software development projects," in Proc. 2010 Fifth International Conference on Internet Monitoring and Protection (ICIMP), 2010.

[4] H. Hijazi, T. Khdour, and A. Alarabeyyat, "A review of risk management in different software development methodologies," International Journal of Computer Applications, vol. 45, no. 7, pp. 8-12, May 2012.

[5] J. Dhlamini, I. Nhamu, and A. Kachepa, "Intelligent Risk Management Tools for Software Development," presented at SACLA '09, Mpekweni Beach Resort, South Africa, 29 June-1 July, 2009.

[6] L. Sarigiannidis and P. D. Chatzoglou, "Software development project risk management: A new conceptual framework," Journal of Software Engineering and Applications, vol. 4, pp. 293-305.

[7] O. E. Ogunsanmi, O. A. Salako, and O. M. Ajayi, "Risk classification model for design and build projects," Journal of Engineering, Project, and Production Management, vol. 1, no.1, pp. 46-60.

[8] A. M. Lima, "Risk assessment on distributed software projects," in Proc. 2010 ACM/IEEE 32nd International Conference on Software Engineering, May 2-8, Cape Town, South Africa, 2010, pp. 349-350.

[9] R. K. Bhujang and V. Suma, "Risk measurement with CTP2 parameters in software development process," ICT and Critical Infrastructure: Proceedings of the 48th Annual Convention of Computer Society of India-Vol II, Advances in Intelligent Systems and Computing, vol. 249, 2014, pp. 491-498.

[10] R. K. Bhujang, P. Raju et al., "Risk prevention technique in software development," in Proc. International Conference on Electrical, Electronics and Computer Engineering, 2013, pp. 86-90.

[11] P. Raju et al., "Risk identification tool for cost and time parameters in software development," in Proc. International Conference on Computer Science and Engineering, 2013, pp. 128-132.

[12] R. K. Bhujang and V. Suma, "A study of risk and CTP ${ }^{2}$ during software development process," presented at IEEE, ICARET-2013, Vijayawada, India.

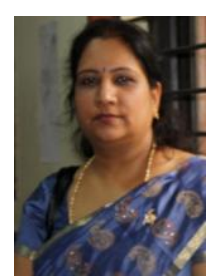

Raghavi K. Bhujang is a research scholar from Jain University, a member of RIIC from DSI, Bangalore. Currently working as an assistant professor in Department of MCA, PESIT, and Bangalore, India. The qualifications of the author are Master of Computer Applications from Bharathidasan University, in the year 2002. At present, she is pursuing $\mathrm{PhD}$ from Jain University, Bangalore.

She has 13 years in total experience, which involves working in software industry for 8 years and teaching as an assistant professor for 5 years in a reputed educational institution. She has worked in several industries like Wipro Technologies as Software Engineer and in IBM as Senior Systems Engineer and Technical Lead. Her work area had the financial domain, where in software development was done on middleware application, specifically on WebSphere products. She has also worked in project management; quality assurance also has taken interviews for the experienced people of the organization.

Raghavi K. Bhujang has made various publications including IEEE and Springer. Her first publication won the 'Best Paper Award' in EISTCON conference conducted in 2012 from IRNet, Bangalore. 


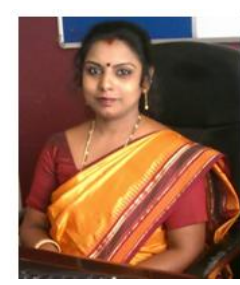

Suma V. has obtained her B.E. in information science and technology, M.S. in software systems and her $\mathrm{Ph} . \mathrm{D}$. in computer science and engineering Dr. Suma is currently the dean at Research and Industry Incubation Centre, Dayananda Sagar Institutions, Bangalore. She has a vast experience of more than 17 years in academics, research and industry interactions. She is a recognized mentor at various universities which includes University of Applied Sciences, Hochschule Hof, Germany, e-mentor through ACM mentor net at Sate Mississippi University. Being a member of IEEE, ACM, Institute of
Engineers and Life member of Computer Society of India, she has published several International publications which include her research articles published in world class international journals such as ACM, ASQ, Crosstalk, IET Software and indexed in NASA, UNI trier, Microsoft, CERN, IEEE, ACM portals, Springer and having several Best Research Awards. She is listed in Marquis Who's Who in the World as a distinguished Scientist and is the Chief Editor, Dayananda Sagar International Journal, Science | Engineering | Management, ISSN (Print) :2347-1603. She is the recipient of Academic Research Award of Excellence by Additive Manufacturing society of India during 2013. 